\title{
Experiences with basic microsurgical training programs and skill assessment methods at the University of Debrecen, Hungary ${ }^{1}$
}

\author{
Norbert Nemeth', Iren Miko", Istvan Furka'
}

'PhD, DSc, Department of Operative Techniques and Surgical Research, Institute of Surgery, Faculty of Medicine, University of Debrecen, Hungary. Conception and design of the study, manuscript preparation and writing, final approval.

"PhD, Department of Operative Techniques and Surgical Research, Institute of Surgery, Faculty of Medicine, University of Debrecen, Hungary. Conception and design of the study, manuscript preparation and writing, final approval.

\begin{abstract}
During the past decades microsurgical training programs together with skill assessment methods had been developing intensively worldwide. Concerning the teaching of basic techniques at various levels, we aimed to summarize the education program types and experiences at our department, in order to define the way of continuity. All in the hope that this summary might contain useful information for other educators as well. About 50 years ago, in the late 1960s, microsurgical basic education had been established in Debrecen. Since the 1990s multilevel education programs have been developed, starting in undergraduate years up to the postgraduate training, residency and continuous medical education programs. In the last three decades about 2,300 participants completed courses, including over 470 residents. The ones who already succeeded microsurgical course as medical students, during residency program could reach better results and skill development. Concluding thoughts, the traditional methods and special experiences are highly important in microsurgical education. The necessary duration and individual training approach are emphasized. Standardization (self and international), comparability, accessibility, providing milestones of microsurgical skills are key factors. Proper feedback and skill assessment (experiences, internationally recognized scores, or combinations) are indispensable, but have to be fitted to the characteristic elements of the course.
\end{abstract}

Key words: Microsurgery. Education, Medical. 


\section{Introduction}

There is a huge demand on effective microsurgical training that provides necessary skill for using the microsurgical technique successfully in the clinical practice. Numerous educational methods are known, based on special local traditions and masters in Austria, Belgium, Brazil, Canada, China, France, Germany, Hungary, Italy, Japan, Korea, Poland, Romania, Spain, Sweden, UK and the USA, among others ${ }^{1-16}$. The necessity of the evaluation of training and the importance of the objective skill assessment methods have been developed together with the programs. ${ }^{4,6,7,9,10,12,17-21}$. Increasing number of papers shows evidences on the effectiveness of well-planned training programs as well ${ }^{22-24}$.

In Debrecen, Hungary, the microsurgical basic education had been established in the late $1960 \mathrm{~s}^{3,4,6,9,10}$. Organized courses have been held since 1986 at graduate and postgraduate levels in Hungarian and English programs. The most intensive and main custom-tailored course is the 80 -hour postgraduate one $e^{6,9,10,16}$. The principles of this microsurgical basic educational program are: activity (the student must be active in practice as well), synchronism (working together with the teacher and/or with under continuous guidance), video-assistance (the teacher's actions, movements and tricks are show on a monitor), self-controlling (by real time monitoring on screen and video/DVD recordings, and the student can fix their work on video and can observe and realize their failures), individualization (custom tailored and based on the individual's skill level and development), and analysis (with the offering constructive criticism of the teacher everyday - pitfall analysis) $3,4,6,9,10,15$.

During the past decades the course programs together with skill assessment aspects and methods had been developing worldwide. Concerning the teaching and practicing of basic techniques at various levels, we aimed to summarize the education program types and experiences at our Department, in order to define the way of continuity. All in the hope that this summary might contain useful information for other educators as well.

\section{Educational programs and the teaching model}

\section{Courses at graduate and postgraduate level}

\section{Elective courses}

Basic microsurgical training has been opened for medical students in 1986. The program has been accredited as a chosen alternative course since 1991. From 1995 till 2008 it was a freely chosen course in the Hungarian and the English Program of our University. In the first two decades the course „Basic microsurgical training. Introduction to microsurgery" ( 4 hours of lectures and 16 hours of practices) course became very popular, and always quickly occupied and fully registered dominantly by the $4^{\text {th }}$-year medical students. In 2008 it became a compulsory chosen course (2 hours of lectures, 10 hours of practices). In the last decade the course exists with the same popularity. The course is aimed to give an introduction to microsurgery, the atraumatic techniques and may initiate further trainings for the individual.

\section{Residency training program}

Since the 2000/2001 academic year microsurgical training has been integrated into the obligatory residents' training program, as part of the "Basic Surgical Techniques" course (two-week course: 2000-2003, threeweek course: 2004-2013), later which was renamed and augmented as "Surgical Skill Training" program (four-week course since the 2013/2014 academic year). 

modules

The program consist of the following

- Surgical Operative Techniques module (1+1 week): Dry" training on surgical phantom models (skin pad, venous cutdown pad). Operative training on different animal-origin biomodels (porcine leg, spleen, liver with gallbladder, aorta and small bowel). Real operating practices on anesthetized pigs (with the necessary permissions): median or paramedian laparotomy, techniques of bowel anastomoses, basic operative techniques of vascular and parenchymal organ surgery, cholecystectomy, vein preparation (venous cutdown technique), tracheostomy, etc.

- Basic Laparoscopic Technique module (1 week): on phantom surgical training models and biomodels (chicken thigh, porcine liver with gallbladder) in pelvi-trainer, and MATT (Minimal Access Therapy Technique) trainer and simulation training unit. Operating laparoscopic cholecystectomy on anesthetized pigs.

- Basic Microsurgical Training module (1 week): scraping letter with needle, pulling of textile fibers dry and wet method, microsurgical suturing and knotting technique on rubber glove, end-to-end anastomosis on biomodels (chicken thigh femoral / sciatic artery).

\section{PhD courses}

For PhD students two 15-hour basic courses are organized: Basics of microsurgery for biomedical research" and Microsurgical techniques", focusing on basic microsurgical practice and experimental microsurgical interventions and methods that can be useful for their further research work.
Continuous medical postgraduate training courses

These courses are aimed to give an immersion into the microsurgical practice with intensive training.

The two-week (80-hour): Basic Microsurgical Training. Introduction to Microsurgery" course is announced for general surgeons, pediatric surgeons, gynecologists, urologists, trauma-orthopedic surgeons, heart surgeons, neurosurgeons, plastic and reconstructive surgeons, oto-laryngologists and researchers. The course is open for veterinary doctors as well. The participants have different educational background, various skill level, diverse capabilities and difference in age as well.

The one-week (40-hour): Advanced Microsurgical Training" and the two-week (80hour) Advanced Microsurgical Techniques" courses are announced for the ones who had completed the "Basic Microsurgical Training" course. These courses focus on practicing and perfecting microvascular anastomoses, with custom-tailored further elements. The courses are recognized by the International Society for Experimental Microsurgery (ISEM), which information is appeared on the certificate of completion.

\section{Special courses}

Microsurgical postgraduate courses for urologists/andrologists: testicle biopsy and suture, anastomosis of the ductus deferens.

In cooperation with the Department of Ophtalmology, microsurgical course for ophthalmologists on biopreparates of animal origin: techniques for corneal sutures, plastic surgical basic techniques around the eye.

\section{Teaching method}

The general curricula of the microsurgical courses $3,6,9,10,15$ are the followings:

I. Learning the theoretical fundamentals: 
Short history of microsurgery, introduction of technical requirements as operating microscopes, microsurgical instruments (straight-, curved-, inverted and jeweler forceps, scissors, needleholders, clips and approximators), microsurgical suture materials and needles, operating microscopes and other equipment.

II. Practicing basic microsurgical skills:

\section{A. Lesson of harmonization:} Practicing on newspapers, scraping printed letters with the fine tip of injection needle. Aim: adaptation to the operating microscope at different magnifications with the movements harmonized. Harmony between eyes and hands, between both hands (bimanual work), improve depth- and distanceperception (Figure $1 A-B$ ).

B. Probe of layer-feeling: Practicing on four-layer gauze sheets models. Separation and pulling of gauze fibers with microsurgical forceps and taking them back without entangling the fibers to preserve the integrity of the gauze sheet. Performing it in the different directions using various magnifications (on dry and wet gauzes). Cutting through the fibers (fiber by fiber) creating a flap from the four-layer gauze sheet model with microsurgical forceps and scissors from the left and right directions (on dry and wet gauzes). Aim: ability to move and orientate in three-dimensional space, sensation of depth- and layer acuity, increasing precision dexterity (Figure $1 \mathrm{C}-\mathrm{F}$ ).

\section{Under-microscopic}

stitching technique: Taking stitches in different directions (10/each) and making knots on a rubber sheet. Aim: Practicing the microsurgical suturing and knotting techniques. Microsurgical knotting with needle-holders and forceps under the microscope at various magnifications (Figure $1 \mathrm{G}-\mathrm{H}$ ).

D. Making microvessel anastomosis: Practice on fresh or frozen-warmedup biopreparate model. Aim: endto-end vascular anastomosis on femoral artery of animal origin biopreparate model or on a chicken thigh model (vessels with 2-5 mm external diameter) Courses for medical student's ends up at this point (Figure $2 A-D$ ).

III. Introduction to using microsurgical techniques: Microsurgery practice on living animal. Performing end-to-end anastomosis at the infrarenal part of the abdominal aorta in anaesthetized rat (for 40 or 80 -hour postgraduate courses) (Figure $2 \mathrm{E}-\mathrm{F}$ ).

IV. Advanced microsurgical techniques: Microsurgery on living animal advanced practices. Performing endto-end anastomoses on the femoral artery and/or common carotid artery, caudal caval vein, femoral vein, endto-side arterio-venous shunt on femoral and saphenous vessels, endto-side porto-caval shunt, autologous renal transplantation in anaesthetized rats (for 40 or 80 -hour postgraduate courses).

V. Further practice possibilities (at levels II/D, III and IV): Non-living models - biopreparates, end-to-end anastomoses on coronary arteries of porcine heart, various vascular and 
peri- and epineural nerve anastomoses on chicken thigh. Additionally to vascular anastomoses, for urologists/ andrologists: ductus deferens one- and two-layer anastomoses and various microsutures on the tunica albuginea of the testis.

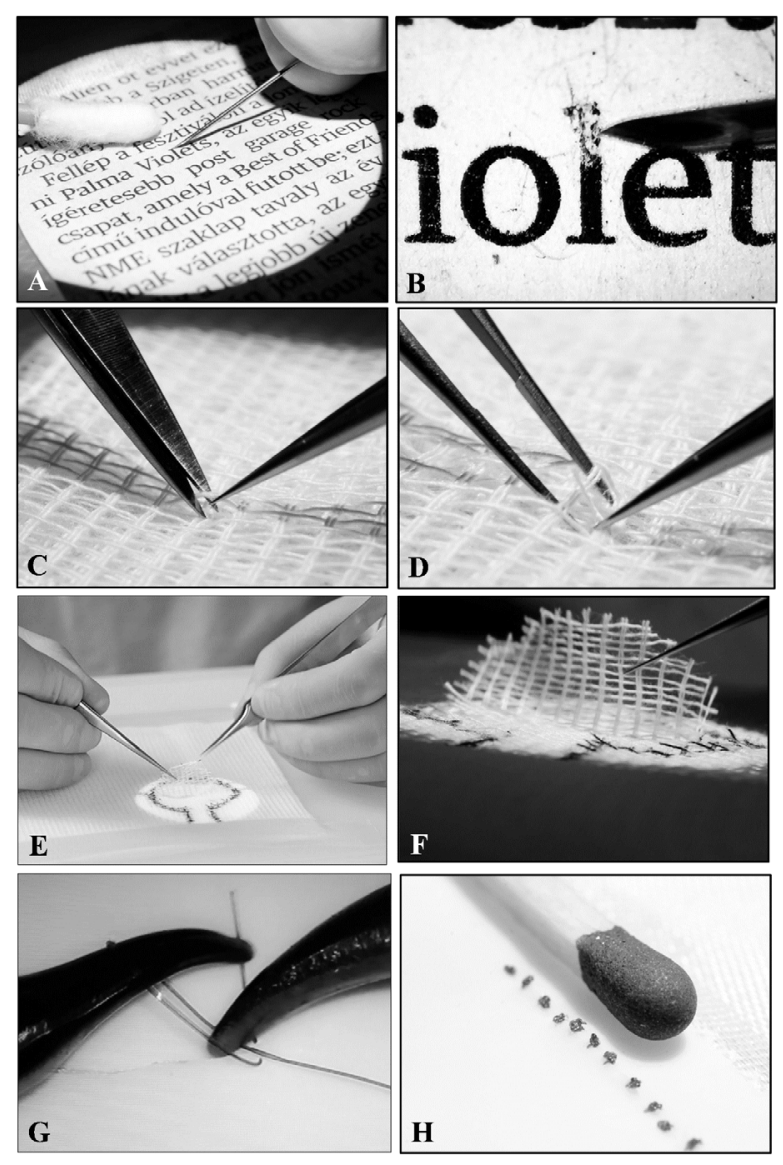

Figure 1 - Main steps and practical elements of the basic microsurgical training program I. A,B: scraping printed letters from a newspaper with needle (with left and right hand, in different directions, at various magnifications); C,D: practicing on textile fibers, preparation and pulling and taking back of textile fibers with microsurgical forceps bimanually (on dry and wet gauze, at various magnifications); E,F: cutting off a flap from the gauze with microsurgical forceps and scissors (on dry and wet gauze, at various magnifications); $\mathbf{G}, \mathbf{H}$ : stitching and making knots on rubber pad (in different directions).
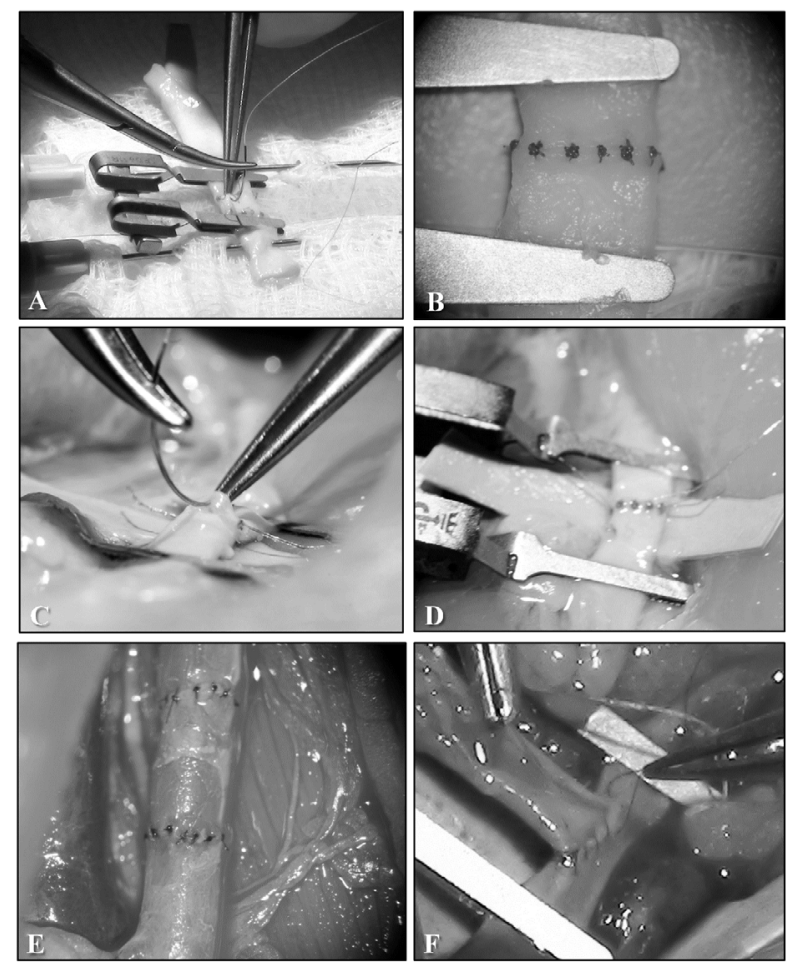

Figure 2 - Main steps and practical elements of the basic microsurgical training program II. A,B: end-to-end anastomosis on biografts (animal origin, e.g. femoral artery of a piglet, $\sim 3-4 \mathrm{~mm}$ outside diameter); C,D: end-to-end anastomosis on biopreparates (chicken thigh, femoral or sciatic arteries, 1.5-2 mm external diameter); E,F: various anastomoses on anesthetized rats (e.g., end-toend, end-to-side anastomoses on infrarenal part of abdominal aorta or on femoral vessels, 0.6-1.5 $\mathrm{mm}$ external diameter).

\section{Evaluation of work and skill assessment during basic microsurgical trainings}

How do we evaluate? What are the milestones of competence and for stepforwards in the microsurgical training program?

1. The beginnings: The proper usage of the magnification on the microscope and the microsurgical instruments (forceps and scissors) during warm-up exercises (scratching of ink from a newspaper, 
pulling and taking fibers on a gauze pad).

Methods of assessment: continuous guidance and qualitative control by the tutor.

2. Knotting and suturing techniques: The sum of the stitching and knotting time with 6-0 or 7-0 monofilament polyamide or polypropylene suture material on a rubber pad goes below 90 seconds in horizontal, vertical and oblique lines. The average knotting score (based on our scoring system) is minimally 8 . Effective handling of suture material while tying. Appropriate tension while tying. The ergonomics is continuous and fluent.

Methods of assessment: continuous guidance, qualitative control by the tutor, measurement of time, detailed analysis of the sutures optionally by modified Global Rating Scale (GRS) and Objective Structured Assessment of Technical Skill (OSATS) scoring systems, or other methods.

3. Creating end-to-end vascular anastomosis on non-living biomodels (chicken thigh, femoral artery): Tissue handling is atraumatic. During passing needle through tissue: the needle does not wobble in the needle holder, needle enters tissue perpendicularly, forceps handles vessel adventitia to provide counter traction, needle is pulled through tissue following its curve, suture is pulled out parallel to the tissue, suture tails are left at the correct length, appropriate depth tissue bite on each side and the sutures are placed appropriately. The score of the modified
GRS for non-living biomodels reaches $75 \%$ of the maximum. The time to create an end-to-end anastomosis with 7-0 or 8-0 monofilament suture material on a femoral artery in a chicken thigh is below 30 minutes.

Methods of assessment: continuous guidance, qualitative control by the tutor, measurement of time, detailed analysis of the sutures possible (GRS, OSATS, etc).

4. Creating end-to-endvascular anastomosis on a living model (anesthetized rat, infrarenal part of the abdominal aorta): Tissue handling is atraumatic. Adequate placement of microvascular clips on the vessel. With 9-0 suture material the max. number of stitches is 8-9. With 10- 0 suture material the max. number of stitches is 9-10. No bleeding, or oozing is stopped after 3-5 minutes of pressing with a swab. No extra stitch is needed. There is no stenosis. Patency is proper (30 minutes later). Quality of the stitches is good (the average knotting score is $\min .8)$.

Methods of assessment: continuous guidance, qualitative control by the tutor, measurement of time, detailed analysis of the sutures possible (GRS, OSATS, etc).

\section{Number of participants}

Table 1 summarizes the participants at various microsurgical courses at the Microsurgical Education and Training Center of the Department. The class-hour increases with the level of specialty. 
Table 1 - Microsurgical course types and participants since the beginnings till June 2018 at the Microsurgical Education and Training Center, Department of Operative Techniques and Surgical Research, Faculty of Medicine, University of Debrecen.

\begin{tabular}{lccc}
\hline Microsurgical course and its duration & Participants & Period & $\begin{array}{c}\text { Number of } \\
\text { participants }\end{array}$ \\
\hline $\begin{array}{l}\text { Basic microsurgical training. Introduction to } \\
\text { microsurgery" (20 hours) }\end{array}$ & $\begin{array}{c}\text { Medical students (4th } \\
\text { and } 5^{\text {th }} \text { year) }\end{array}$ & $1986-2008$ & 564 \\
$\begin{array}{l}\text { Basic microsurgical training. Introduction to } \\
\text { microsurgery" (12 hours) }\end{array}$ & $2009-2018$ & 875 \\
$\begin{array}{l}\text { Basics of microsurgery for biomedical research" and } \\
\text { Microsurgical techniques" (15+15 hours) }\end{array}$ & PhD students & $1997-2018$ & 291 \\
$\begin{array}{l}\text { Microsurgical training" as a module of the Surgical skill } \\
\text { training" course (12/20 hours) }\end{array}$ & Residents & $1999-2018$ & 476 \\
$\begin{array}{l}\text { Basic Microsurgical Training" (80 hours) } \\
\text { Sum: }\end{array}$ & Postdoctors, specialists & $1986-2018$ & 100 \\
\hline
\end{tabular}

\section{Skill assessment and feed-backs}

Figure 3 shows an example of skill assessment chart completed during a basic course for medical students. It could be stated that the proper feedback and assessment of skills during the medical students' basic microsurgical training is a constructive method to help the participant to continue their skill training and emphasize the point out where the correction should be made.
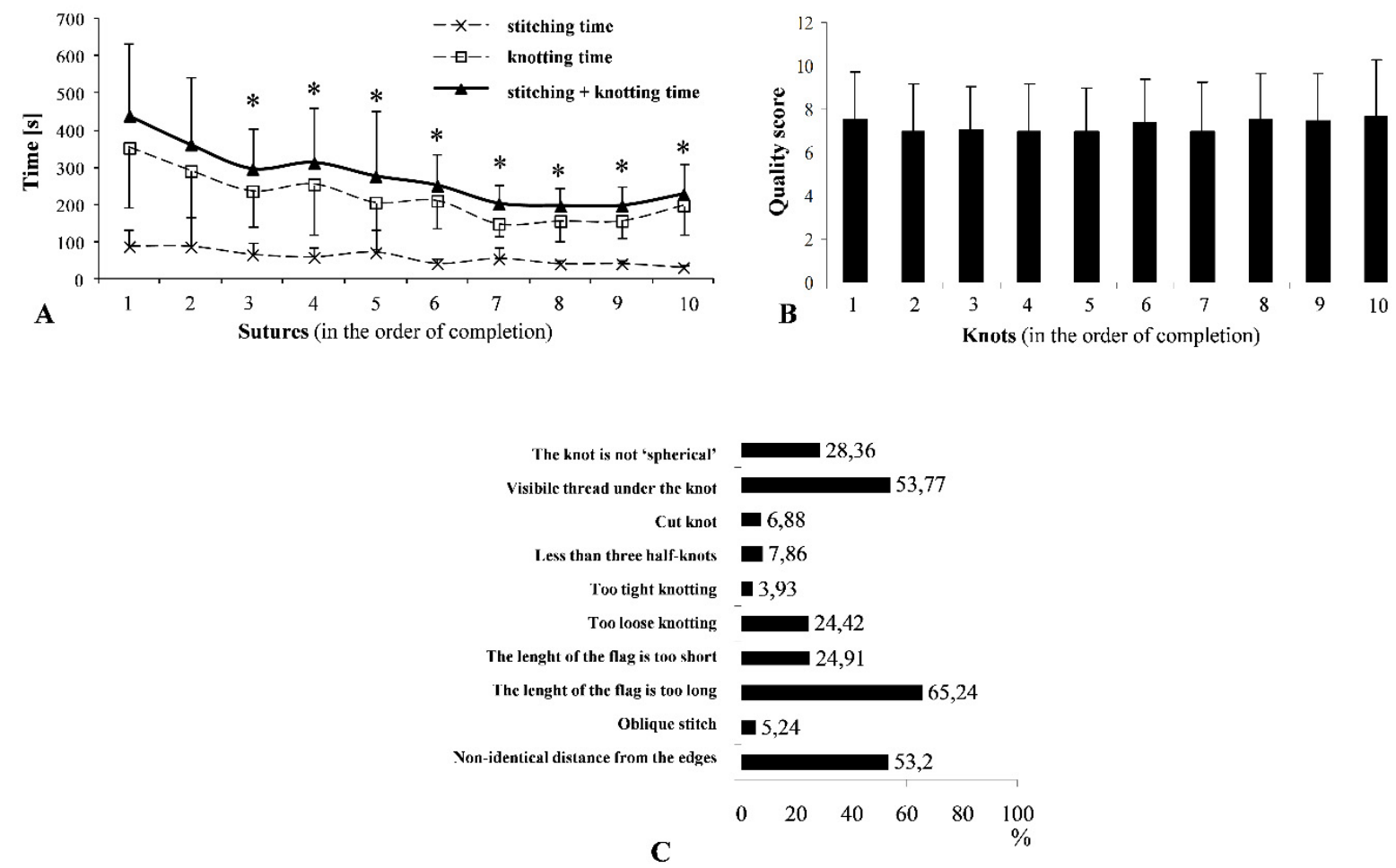

Figure 3 - An example chart for general skill assessment taken during basic microsurgical course for medical students. A: Duration of taking stitches and knotting (10 sutures after learning the method; means \pm S.D., ${ }^{*} p<0.05$ vs. the first suture, one-way/repeated measure ANOVA test); B: quality scoring of the individual sutures; C: percents of the general mistakes and pitfalls. 
As part of the "Surgical skill training" course, the microsurgical module provided special practice of the residents. From all the related disciplines of operative medicine the residents found the microsurgical module very useful, and most of them were enthusiastic learning more atraumatic work together with the fundamentals of microsurgical procedures. Important observation was that the residents who already completed microsurgical course before as medical students, in this residency training program they could have significantly better results in their microsurgical skill level and in further individual skill development. This result enforce the importance of the multilevel microsurgical training programs starting during the medical school years.

\section{Discussion}

On microsurgical education and training numerous papers have been published in the last two decades, which articles mostly focus on the methods helping the effectiveness of the training, providing models and definitive educational programs ${ }^{1-16}$. Since for the obtainment and practicing safe stitching and suturing techniques, atraumatic tissue preparation, fine and precise movements well-established and well-controlled practical programs are needed. However, the methodological palette, as for educational programs, is very colorful. On the websites, containing the course announcements, the teaching method cannot be necessarily identified because the programs are often linked to definitive persons, traditions and schools. On the other hand there is a need for the skill assessment, and so the supply and the demand must meet.

Concerning the microsurgical courses it is important to emphasize the 3Rs (replacement, reduction and refinement). For the surgical safety and successful microsurgical work in the clinical practice, it is necessary to practice on living tissue, but after a well-established microsurgical skill level acquired during trainings on various models and biopreparates. If the participant does not reach a certain level of skill, he/she is not allowed to work on living tissue (anesthetized rat).

In a previous study we analyzed a sample out of the courses found on the web (91 courses' data from 21 countries) it became obvious that: (1) The demand for microsurgical training opportunities is high worldwide, although the accessibility is altering. (2) Accessibility is influenced by numerous entrance barriers, such as maximal number of applicants, number of microscopeworkstations and tutors, and the amount of registration/tuition fee, among others. (3) The offered hours vary in a wide range. (4) There are only a few courses that provide trainings over 40 hours at a decent price, offering a relatively low class-hour/price ratio ${ }^{24}$.

By our opinion, for learning basics of microsurgery 8-16 hour courses cannot be effective. The aim is to develop the skill for the participant. The short course is too long for an introduction but not enough for the effectiveness. For the one who already trained that is another question.

The skill assessment is inevitable during any kind of microsurgical course. However there is no uniformly accepted method or guideline. In Debrecen the skill assessment of the microsurgical courses firstly focused on the direct quality evaluation. Later, keeping the strong quality control the system developed with a stepwise inclusion of objective parameters.

Standardization of education methods and skill assessment is an old and important desire of several societies over the past decades, rising again and again since the $1970 s^{1,2,17,20,25-27}$. The most important issue is to acquire the necessary microsurgical skill. Thus, determination of the skill level and clear 
definition of milestones are important. The methods reaching those 'key competencies' are naturally different. Comparability is important, so a kind of standardization is needed, but the importance of the individuals, the tutors themselves, the style, the art and traditions should not be neglected. Therefore quality assurance is considered much more important. The 'long-term' effectiveness is a key question and the importance of feed-backs, including the real feed-back: the patients' benefit, the art of the surgeon that hopefully had been improved also by the successfully completed microsurgical course (Figure 4).

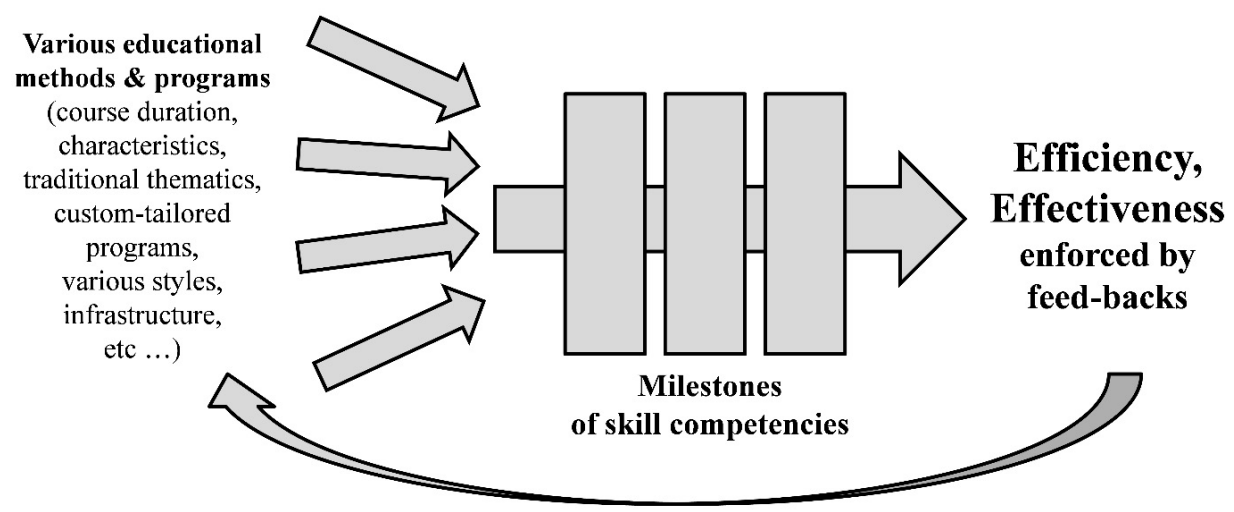

Figure 4 - The importance of the variety of microsurgical education programs leading the participant to certain level of skill (milestones of skills and competencies), and the necessity of short-term and long-term feed-back.

Perhaps most of the standardization protocols, publications, comparative analyses mainly focus on the clinical microsurgical skills. Regarding various organ and tissue transplantation models in rodents and considering the quality and the time factor, in the field of experimental microsurgery, certain milestones fall within different assessment and quite different dimension ${ }^{28-30}$.

Overviewing the tematics and the existing quality assurance can be tools to evaluate the courses and supported accordingly by professional international societies (e.g., International Society for Experimental Microsurgery, European Society for Surgical Research, International Microsurgical Simulation Society, etc).

Concluding the thoughts and aspects: (1) The traditional methods, special experiences (leader mentors, tutors) are highly important in microsurgical education. (2) The necessary duration (above 40 hours) and individual training are emphasized. (3) Standardization (self- and international), comparability, accessibility, reaching milestones of microsurgical skills, all are key factors in the success of microsurgical courses. Proper feedback and assessment of the technique during the training is a constructive method to help the participant to continue their skill training and emphasize the point out where the correction should be made.

\section{References}

1. Habal SM, Fitzpatrick HF, Green GE. Training in microvascular surgery. Surgery. 1977;81:596-8. PMID: 850876.

2. Lee $S$, Diez-Pardo J, Olszewski W, Rowinski W, Hirner A, Brekke I, Swedenborg J, Flatmark U, Häring A, Nylander G, Orloff MJ. An improved microsurgical course for a mixed group of surgeons. World J Surg. 1981;5:285-94. PMID: 7245798.

3. Bekesi L, Miko I, Varga S, Furka I. Can a medical student be motivated to study 
microsurgery? Acta Chir Austr. 1994;26:17-8.

4. Furka I, Mikó I, Brath E. Teaching microsurgery at the University Medical School of Debrecen, Hungary. Abstract Book of the 4th Congress of the International Society for Experimental Microsurgery, London/Ontario Canada, 1998.

5. Di Cataldo A, Puleo S, Rodolico G. Three microsurgical courses in Catania. Microsurgery. 1998;18:449-53. PMID: 9888348.

6. Miko I, Brath E, Furka I. Basic teaching in microsurgery. Microsurgery. 2001;21:121-3. PMID: 11494375.

7. Klein I, Steger U, Timmermann W, Thiede A, Gassel HJ. Microsurgical training course for clinicians and scientists at a German University hospital: a 10-year experience. Microsurgery. 2003;23:461-5. PMID: 14558003.

8. Uson-Gargallo J, Viguera-Salvago FJ, Calles-Vazquez C. Interactive advancedcommunication multistation system for microsurgical training. Microsurgery. 2004;24:218-22. PMID: 15160381.

9. Furka I, Brath E, Nemeth N, Miko I. Learning microsurgical suturing and knotting techniques: comparative data. Microsurgery. 2006;26:4-7. PMID: 16444711.

10.Furka I, Brath E, Nemeth N, Miko I. Gondolatok a mikrosebészeti oktatásról. Mire volt elég az 5460 óra a mikrosebészeti alapoktatásban? [Conceptions about microsurgical education. What were 5,460 hours of microsurgical basic education enough for?]. Magy Seb. 2006;59:147-51. PMID: 16937788.

11.Blidisel A, Jiga L, Nistor A, Dornean V, Hoinoiu $B$, lonac $M$. Video-assisted versus conventional microsurgical training: a comparative study in the rat model. Microsurgery. 2007;27:446-50. PMID: 17603812.

12.Chan WY, Matteucci P, Southern SJ. Validation of microsurgical models in microsurgery training and competence: a review. Microsurgery. 2007;27:494-9. PMID: 17596849.

13. Martins PN, Montero EF. Basic microsurgery training: comments and proposal. Acta Cir Bras. 2007;22:79-81. PMID: 17293955.

14.Ramachandran S, Chui CH, Tan BK. The chicken aorta as a simulation-training model for microvascular surgery training. Arch
Plast Surg. 2013;40:327-9. PMID: 23898426. 15. Furka I, Mikol. Mikrosebeszeti alapismeretek [Introduction to microsurgery]. 2nd enlarged edition. Debrecen: Debrecen University Press; 2011.

16. Nemeth N, Furka I, Miko I. Educational and research activity of the Department of Operative Techniques and Surgical Research, Institute of Surgery at the Medical and Health Science Center, University of Debrecen in Hungary. Acta Cir Bras. 2013;28:403-6. PMID: 23702945.

17.Starkes JL, Payk I, Hodges NJ. Developing a standardized test for the assessment of suturing skill in novice microsurgeons. Microsurgery. 1998;18:19-22. PMID: 9635789.

18. Moorthy K, Munz Y, Sarker SK, Darzi A. Objective assessment of technical skills in surgery. BMJ. 2003;327:1032-7. PMID: 14593041.

19.Chan WY, Niranjan N, Ramakrishnan V. Structured assessment of microsurgery skills in the clinical setting. J Plast Reconstr Aesthet Surg. 2010;63:1329-34. PMID: 19625227.

20.Ramachandran S, Ghanem AM, Myers SR. Assessment of microsurgery competencywhere are we now? Microsurgery. 2013;33:406-15. PMID: 23712917.

21. Oltean M, Sassu P, Hellstrom M, Axelsson $P$, Ewaldsson $L$, Nilsson $A G$, Axelsson $M$. The microsurgical training programme in Gothenburg, Sweden: Early experiences. J Plast Surg Hand Surg. 2017;51:193-8. PMID: 27687892.

22.Lin TS, Chiang YC. Correlation between microsurgical course performance and future surgical training selection by intern and junior residents. Microsurgery. 2008;28:171-2. PMID: 18253943.

23. Mucke T, Borgmann A, Ritschl LM, Kesting MR, Loeffelbein DJ, Wolff KD. Microvascular training of medical students and surgeons - a comparative prospective study. J Craniomaxillofac Surg. 2013;41:e187-e90. PMID: 23402732.

24.Nemeth N. Posztgradualis mikrosebeszeti gyakorlati kurzusok szervezesi es oktatasmarketing vonatkozasai. [Organizational end education marketing relations of postgradual microsurgical training courses]. MBA graduation thesis. University of Debrecen; 2013. 
25.Di Cataldo A, La Greca G, Rodolico M, Candiano C, Li Destri G, Puleo S. Experimental models in microsurgery. Microsurgery. 1998;18:454-9. PMID: 9888349.

26. Komatsu S, Yamada K, Yamashita S, Sugiyama N, Tokuyama E, Matsumoto K, Takara A, Kimata Y. Evaluation of the microvascular research center training program for assessing microsurgical skills in trainee surgeons. Arch Plast Surg. 2013;40:214-9. PMID: 23730596.

27.Leung CC, Ghanem AM, Tos $P$, lonac $M$, Froschauer S, Myers SR. Towards a global understanding and standardisation of education and training in microsurgery. Arch Plast Surg. 2013;40:304-11. PMID: 23898423.

28. Lee S. Connections between experimental microsurgery and general surgery. Microsurgery. 1998;18:445-5. PMID: 9888346.

29.Tolba RH, Czigány Z, Osorio Lujan S, Oltean M, Axelsson $M$, Akelina $Y$, Di Cataldo A, Miko I, Furka I, Dahmen U, Kobayashi E, Ionac $M$, Nemeth N. Defining standards in experimental microsurgical training: recommendations of the European Society for Surgical Research (ESSR) and the International Society for Experimental Microsurgery (ISEM). Eur Surg Res. 2017;58:246-62. PMID: 28746936.

30.Furka I. Tribute to the memory of Professor
Sun Lee. Magy Seb. 2018;71:27-30. PMID: 30084663.

\section{- Acknowledgements}

The staff members of the Department of Operative Techniques and Surgical Research, Faculty of Medicine, University of Debrecen, and all the former and current tutors who took part in microsurgical education programs at a certain level in the past three decades (Dr. Papp L., Dr. Simon G., Orszagh L., Palagyi I., Dr. Kanyari Zs., Vincze A., Mizsak L., Dr. Bekesi L., Dr. Varga S., Dr. Toth-Martinez A., Dr. Toth A., Dr. Brath E., Dr. Klarik Z., Dr. Hever T., Dr. Toth E., Dr. Matyas L., Dr. Sajtos E., Dr. Kiss F., Dr. Lesznyak T., Dr. Magyar Zs., Dr. Mester A., Dr. Ghanem S., Dr. Szabo B., Dr. Varga G.). We are grateful for the clinicians who contributed to the special microsurgical education courses (Dr. Csutak A. of Department of Ophthalmology, Dr. Benyo M. of Department of Urology, Faculty of Medicine, University of Debrecen). Special thanks to the microsurgical assistants Mrs. Somlyaine Balogh E., Mrs. Godenyne Szasz R. and Mrs. Borosne Som Cs.

The work has been dedicated to the memory of Professor Sun Lee (1920-2015).

\section{Correspondence:}

Norbert Nemeth

Department of Operative Techniques and Surgical Research

Institute of Surgery, Faculty of Medicine, University of Debrecen

H-4032 Debrecen, Nagyerdei krt. 98. Hungary

Phone/Fax: +36-52-416-915

nemeth@med.unideb.hu

Received: May 06, 2018

Review: July 09, 2018

Accepted: Aug 04, 2018

\section{Conflict of interest: none}

Financial source: none

\begin{abstract}
${ }^{1}$ Research performed at Department of Operative Techniques and Surgical Research, Institute of Surgery, Faculty of Medicine, University of Debrecen, Hungary.
\end{abstract}

